\section{Tropical Journal of Ophthalmology and Otolaryngology}

2020 Volume 5 Number 8 November-December

\title{
Analysis of visual outcome of Neodymium: Yttrium-Aluminum -Garnet (Nd: YAG) laser capsulotomy in patients with Posterior Capsule Opacification
}

\author{
Deepa R. ${ }^{1 *}$, A. Veeramani V. ${ }^{2}$ \\ DOI: https://doi.org/10.17511/jooo.2020.i08.03 \\ 1* Deepa R., Junior Resident, Department of Ophthalmology, Saveetha Medical College, Chennai, Tamil Nadu, India. \\ 2 V. Panimalar A. Veeramani, Assistant Professor, Department of Ophthalmology, Saveetha Medical College, Chennai, Tamil Nadu, India.
}

\begin{abstract}
Objective: Posterior capsular opacification (PCO) is a postoperative complication causing decreased visual acuity. This study aims to study the efficacy of Nd: YAG laser capsulotomy in posterior capsular opacification following cataract surgery by analyzing the visual outcome. Material and Methods: A prospective study included a sample size of 50 eyes of 37 patients with Posterior capsular opacification following uneventful cataract surgery with significantly decreased visual acuity. Detailed anterior and posterior segment examination was done, best-corrected visual acuity (BCVA) was recorded along with measurement of IOP. Posterior capsulotomy was performed using Nd: YAG laser (Neodymium: Yttrium-aluminum-garnet) and patients were followed up. Visual acuity was assessed and complications if any were recorded. Results: It was noted that $74 \%$ of the patients at the end of $1^{\text {st }}$ week and $78 \%$ of the patients at the end of $1^{\text {st }}$ and $3^{\text {rd }}$ month had significant visual improvement following Nd: YAG laser capsulotomy. There was a statistically significant difference in Post Nd: YAG laser BCVA on follow up with P-value $<0.001$. Complications encountered were the rise in IOP in $6 \%$ of the population at the end of 1 hour and $1^{\text {st }}$ day of the procedure, iris bleeding was noted in $4 \%$ of the population, intraocular lens damage in $2 \%$, and cystoid macular edema in $2 \%$ of the study population.
\end{abstract}

Keywords: Nd: YAG laser capsulotomy, Posterior capsular opacification

Corresponding Author

Deepa R., Junior Resident, Department of Ophthalmology, Saveetha Medical College, Chennai, Tamil Nadu, India.

Email: deepamoorthy16@gmail.com
How to Cite this Article

Deepa R, A Veeramani VP. Analysis of visual outcome of Neodymium: Yttrium-Aluminum -Garnet ( $\mathrm{Nd}$ : YAG) laser capsulotomy in patients with Posterior Capsule Opacification. Trop J Ophthalmol Otolaryngol. 2020;5(8):216-223. Available From

https://opthalmology.medresearch.in/index.php/jooo /article/view/175

\section{To Browse}

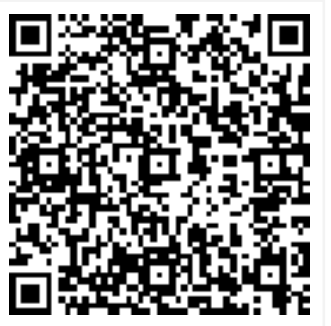

Manuscript Received 2020-11-26

Conflict of Interest No
Review Round 1 2020-12-02

Funding $\mathrm{Nil}$
Review Round 2 2020-12-12

Ethical Approval Yes
Review Round 3

Accepted 2020-12-28

Plagiarism X-checker $8 \%$ 


\section{Introduction}

Posterior capsular opacification (PCO) is a complication following cataract surgery which causes optic clarity disturbances and decreased visual acuity [1]. PCO is caused due to proliferation and migration of residual lens epithelial cells within the posterior capsular bag $[2,3]$ and the incidence of patients requiring neodymium: Yttriumaluminum-garnet(Nd: YAG) laser capsulotomy postoperatively range from $2 \%$ to $50 \%$ [4]. To improve vision in patients with PCO, Nd: YAG laser capsulotomy is done which is a relatively noninvasive procedure and serves as an excellent treatment modality [5,6]. Aron-Rosa and Fankhauser et al [3] proposed Nd: YAG laser capsulotomy as an effective treatment for PCO in the 1980s, it is generally a safe and successful procedure but documented complications include a transient rise in intraocular pressure, corneal edema, iris bleeding, uveitis, lens subluxation or dislocation, lens pitting, retinal detachment, cystoid macular edema and endophthalmitis [3]. Through the 1980s and early 1990s, the incidence of PCO ranged between $25-50 \%$.PCO is a major problem in pediatric cataract surgery where the incidence approaches $100 \%$ [7]. This study aims to study the efficacy of Nd: YAG laser capsulotomy in posterior capsular opacification following cataract surgery by analyzing the visual outcome.

\section{Materials and Methods}

This study was conducted after obtaining Institutional Ethical Committee clearance in the Outpatient department at Saveetha Medical College and Hospital for 6 months A Prospective study included a sample size of 50 eyes of 37 patients and study was conducted after obtaining an informed and written consent from all the patients.

Based on the previous hospital records, the approximate number of potential Eligible subjects attending the study setting during the data collection period were considered as 500 . Hence a finite population correction was applied for 500 . The sample size was calculated assuming the proportion of Visual outcome as $65 \%$. Other parameters considered for sample size calculation were $12.8 \%$ absolute precision and 95\% confidence level. The following formula was used for sample size calculation. The following formula was used for sample size
$n^{\prime}=\frac{N Z^{2} P(1-P)}{d^{2}(N-1)+Z^{2} P(1-P)}$

Where $n=$ Sample size

$N=$ Population Size $=500$

$Z=Z$ statistic for a level of confidence level $=1.960$

$P=$ Expected prevalence/proportion of outcome= 0.65

$D=$ Precision $=0.128$

The required sample size as per the abovementioned calculation was 48 . To account for a nonparticipation rate/ loss to follow up rate of about $5 \%$, another 2 , subjects will be added to the sample size. Hence the final required sample size would be 50.

Statistical methods: Visual outcome was considered as the primary outcome of interest. Descriptive analysis was carried out by mean and standard deviation for quantitative variables, frequency, and proportion for categorical variables. Data is represented using appropriate diagrams like bar and pie diagrams. The association between categorical explanatory variables and the quantitative outcome was assessed by comparing the mean values. The mean differences along with their 95\% Confidence interval were presented. Independent sample t-test/ ANOVA was used to assess statistical significance.

The association between explanatory variables and categorical outcomes was assessed by crosstabulation and comparison of percentages. Odds ratio along with $95 \%$ CI presented. Chi-square test/ Fisher's was used to test statistical significance. Univariate binary logistic regression analysis was performed to test the association between the explanatory variables and outcome variables. Variables with statistical significance in univariate analysis were used to compute multivariate regression analysis. P-value $<0.05$ was considered statistically significant. Data were analyzed by using SPSS software for windows.

Inclusion criteria: Pseudophakic patients with posterior capsule opacification following an uneventful small incision cataract surgery (SICS) with evident decreased visual acuity were included in the study. 
Exclusion criteria: Includes patients with corneal scars or edema, uveitis, posterior segment pathologies, high myopes, and uncooperative patients

Detailed ophthalmic examination was done which included a slit-lamp examination of the anterior segment, fundus examination by direct and indirect ophthalmoscope, best-corrected visual acuity (BCVA) using Bailey Lovie log MAR charts, and measurement of intraocular pressure by Goldmann applanation tonometry. Assessment of PCO on slit lamp-acquired retro-illumination images after complete mydriasis was done. Type of PCO was noted as fibrous, pearly, and mixed type. Clinical grading of PCO was done (Grade 0-Posterior capsule completely clear and no Lens epithelial cells (LEC) migration; Grade 1-LEC migration at the periphery with a clear visual axis; Grade 2-LEC migration onto the visual axis with no drop in best-corrected visual acuity (BCVA); Grade 3-LEC migration onto the visual axis with BCVA better than 6/12; Grade 4LEC migration onto the visual axis and BCVA of $6 / 12$ worse). Grade 4 PCO was considered as visually significant PCO and was considered as an indication for Nd-YAG capsulotomy. Under topical anesthesia, the posterior capsulotomy was performed with $\mathrm{Nd}$ : YAG laser, usually starting with $1-2 \mathrm{MJ} /$ pulse and gradually increased until the desired responses were obtained. Steroid eye drops were prescribed to all the patients for one week. Post laser follow up was done at 1 hour, 1 day, 1 week, 1 month, 3 months of the procedure, and during each visit best-corrected visual acuity using Bailey Lovie logMAR charts, IOP measurement, anterior and posterior segment examination was done and if any complications occurred was also recorded.

\section{Results}

Among the study population of 50 eyes of 37 patients, the mean age of the patients was $56.4 \pm 5.63$ years (Figure 1 ) and males (59.4\%) were more in number than females $(40.5 \%)$ (Figure 2 ). The time interval between cataract surgery and the development of posterior capsular opacification is depicted in Table 1 . Most of the patients in the study group, presented with PCO which was 1-5 years following cataract surgery (46\%). Types of PCO observed in the patients is shown in Table 2, $44 \%$ of patients presented with the fibrous type of PCO.

Fig-1: Age distribution.

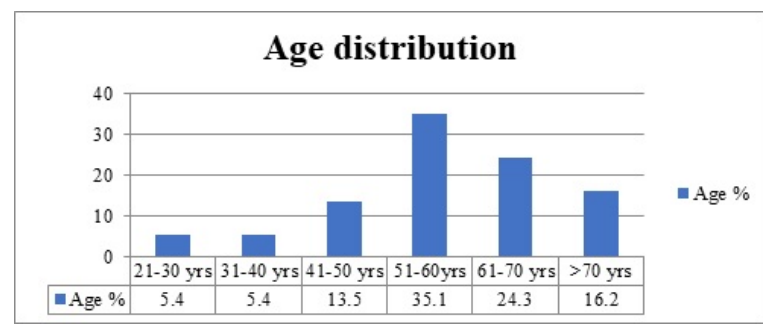

Fig-2: Gender distribution.

\section{Gender distribution}

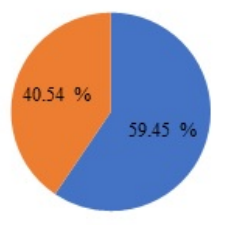

- Male

- Fem ale

Table-1: Time interval between cataract surgery and the development of PCO.

\begin{tabular}{|l|l|l|}
\hline \multicolumn{1}{|c|}{ Duration from surgery } & Number of eyes & Percentage \\
\hline 3 months -6 months & 9 & 18 \\
\hline$>6$ months -1 year & 13 & 26 \\
\hline 1.1 year -5 years & 23 & 46 \\
\hline 5.1 year -10 years & 4 & 8 \\
\hline$>10$ years & 1 & 2 \\
\hline
\end{tabular}

Table-2: Types of PCO.

\begin{tabular}{|l|l|l|}
\hline \multicolumn{1}{|c|}{ Type of PCO } & \multicolumn{1}{c|}{ Number of eyes } & Percentage \\
\hline Fibrous type & 22 & 44 \\
\hline Pearl type & 16 & 32 \\
\hline Mixed type & 12 & 24 \\
\hline
\end{tabular}

Table-3: Distribution of study group based on Pre Nd: YAG laser capsulotomy BCVA $(n=50$ eyes).

\begin{tabular}{|l|l|l|}
\hline \multicolumn{1}{|c|}{ Pre laser BCVA } & \multicolumn{1}{c|}{ Number of eyes } & Percentage \\
\hline$<3 / 60$ & 10 & 20 \\
\hline $3 / 60-6 / 60$ & 25 & 50 \\
\hline $6 / 36-6 / 18$ & 15 & 30 \\
\hline
\end{tabular}

Best-corrected visual acuity was documented pre and post-laser as shown in Tables 3 and 4. Among the study population, at the end of 3 months of the procedure, BCVA of $78 \%$ of the patients improved to $6 / 12-6 / 6$ and $20 \%$ of them improved to $6 / 36$ $6 / 18$ and 1 (2\%) patient had poor visual acuity following capsulotomy. There was a statistically significant difference in Post Nd: YAG laser Bestcorrected Visual acuity on follow up with P-value $<0.001$. (Table 4). The amount of IOP rise following $\mathrm{Nd}$ : YAG laser capsulotomy was noted at each follow-up visit which was measured using the 
Goldmann Applanation Tonometer. Around 6\% of the patients showed a transient increase in IOP $(>21 \mathrm{mmHg}$ ) after 1 hour and 1 day of the procedure and there was no elevation of IOP on further follow-up visits of the patients. There was no statistically significant difference in Pre and Post $\mathrm{Nd}$ : YAG laser measurement in IOP $(\mathrm{mmHg})$ with $\mathrm{P}$ value 0.217. (Table 5). Complications following laser were recorded which included iris bleeding with minimal hyphema in $4 \%$ of the study population, intraocular lens damage in $2 \%$ and cystoid macular edema was observed in $2 \%$ of the study population which was treated appropriately (Table 6).

Table-4: Distribution of study group based on Post Nd: YAG laser capsulotomy BCVA ( $n=50$ eyes).

\begin{tabular}{|c|c|c|c|c|c|c|}
\hline \multirow{2}{*}{$\begin{array}{c}\text { Follow } \\
\text { Up }\end{array}$} & \multicolumn{4}{|c|}{ Visual Acuity } & \multirow{2}{*}{$\begin{array}{c}\text { Chi- } \\
\text { square }\end{array}$} & \multirow{2}{*}{ P-value } \\
\hline & $\begin{array}{l}\text { Visual } \\
\text { Acuity < } \\
3 / 60\end{array}$ & \begin{tabular}{|l} 
Visual \\
Acuity $3 / 60$ \\
$-6 / 60$
\end{tabular} & $\begin{array}{l}\text { Visual } \\
\text { Acuity } \\
6 / 36-6 / 18\end{array}$ & $\begin{array}{l}\text { Visual } \\
\text { Acuity } \\
6 / 12-6 / 6\end{array}$ & & \\
\hline 1 Hour & $2(4 \%)$ & $12(24 \%)$ & $18(36 \%)$ & $18(36 \%)$ & \multirow[t]{5}{*}{48.98} & \multirow[t]{5}{*}{$\mid<0.001$} \\
\hline 1 Day & $0(0 \%)$ & $6(12 \%)$ & $20(40 \%)$ & $24(48 \%)$ & & \\
\hline 1 Week & $0(0 \%)$ & $1(2 \%)$ & $12(24 \%)$ & $37(74 \%)$ & & \\
\hline 1 Month & $0(0 \%)$ & $1(2 \%)$ & $10(20 \%)$ & $39(78 \%)$ & & \\
\hline $\begin{array}{l}3 \\
\text { Months }\end{array}$ & $0(0 \%)$ & $1(2 \%)$ & $10(20 \%)$ & $39(78 \%)$ & & \\
\hline
\end{tabular}

Table-5: Distribution of study group based on the measurement of IOP before and after the laser( $\mathbf{n}=\mathbf{5 0}$ eyes $)$

\begin{tabular}{|c|c|c|c|c|c|c|c|c|}
\hline \multirow{2}{*}{$\begin{array}{c}\text { IOP } \\
(\mathrm{mmhg})\end{array}$} & \multirow{2}{*}{$\begin{array}{l}\text { Pre-Laser } \\
\qquad(\mathrm{N}=50)\end{array}$} & \multicolumn{5}{|c|}{ Follow $U p(N=50)$} & \multirow{2}{*}{$\begin{array}{c}\text { Chi- } \\
\text { square }\end{array}$} & \multirow{2}{*}{ Value } \\
\hline & & $\begin{array}{l}1 \\
\text { Hour }\end{array}$ & 1Day & $\begin{array}{l}1 \\
\text { Week }\end{array}$ & $\begin{array}{l}1 \\
\text { Month }\end{array}$ & 3 & & \\
\hline $11-15$ & $22(44 \%)$ & $\begin{array}{l}24 \\
(48 \%)\end{array}$ & $\begin{array}{l}22 \\
(44 \%)\end{array}$ & $\begin{array}{l}24 \\
(48 \%)\end{array}$ & $\begin{array}{l}25 \\
(50 \%)\end{array}$ & $\begin{array}{l}26 \\
(52 \%)\end{array}$ & 13.128 & 0.217 \\
\hline $16-20$ & $28(56 \%)$ & $\begin{array}{l}23 \\
(46 \%)\end{array}$ & \begin{tabular}{|l|}
25 \\
$(50 \%)$
\end{tabular} & $\begin{array}{l}26 \\
(52 \%)\end{array}$ & $\begin{array}{l}25 \\
(50 \%)\end{array}$ & $\begin{array}{l}24 \\
(48 \%)\end{array}$ & & \\
\hline$>21$ & $0(0 \%)$ & $\begin{array}{l}3 \\
(6 \%)\end{array}$ & \begin{tabular}{|l|}
3 \\
$(6 \%)$
\end{tabular} & $\begin{array}{l}0 \\
(0 \%)\end{array}$ & $\begin{array}{l}0 \\
(0 \%)\end{array}$ & $0(0 \%)$ & & \\
\hline
\end{tabular}

Table-6: Complications following Nd: YAG laser capsulotomy.

\begin{tabular}{|l|l|l|}
\hline \multicolumn{1}{|c|}{ Complications } & Number of eyes & Percentage \\
\hline Intraocular pressure elevation & 3 & 6 \\
\hline Iris bleeding & 2 & 4 \\
\hline Intraocular lens damage & 1 & 2 \\
\hline Cystoid macular edema & 1 & 2 \\
\hline
\end{tabular}

\section{Discussion}

Posterior capsular opacification results from the growth and abnormal proliferation of LECs on the capsule at the time of cataract surgery.
These cells migrate to the posterior capsule where they approach the central visual axis and cause visual axis obscuration, resulting in the dimness of vision. The PCO has two types, fibrous and pearly type. Sometimes a combination of both is also found.

The Lens Epithelial Cells (LEC) that line the anterior capsule is believed to be responsible for fibrous PCO. Clinically it is seen as a wrinkling on the posterior capsule at the site of fusion of the anterior and posterior capsules. The LECs lining the preequatorial zone is responsible for the pearl or proliferative PCO [8-12].

This study reveals that Nd: YAG laser capsulotomy is effective for the treatment of posterior capsular opacification following cataract surgery. The mean age of the patients presented in our was $56.4 \pm 5.63$ years. Males (59.4\%) were more in number than females $(40.5 \%)$.

The maximum time interval between cataract surgery and development of posterior capsular opacification is 1 to 5 years 23 eyes (46\%). The most common type of PCO found in the present study was fibrous type 22 eyes (44\%) [13-18].

Various innovations in the grading system have been reported in the literature. According to the Madurai PCO grading scale. No PCO- No evidence of Posterior Capsule Opacification (PCO) seen before and after pupillary dilation to a minimum of $6 \mathrm{~mm}$. With a direct ophthalmoscope, a clear view of the optic disc, blood vessels, and the nerve fiber layer is obtained. Grade I is No central PCO seen. PCO is seen only with the pupil dilated to a minimum of 6 $\mathrm{mm}$.

With a direct ophthalmoscope, a clear view of the optic disc, blood vessels, and the nerve fiber layer is obtained. Grade II is PCO present in the central visual axis, detectable in an undilated pupil. With a direct ophthalmoscope, there is a mild obscuration of fundus detail, in that the optic nerve head is seen but the retinal nerve fiber layer and the blood vessels are not seen.

Grade III is a PCO present in the central visual axis with an undilated pupil. With a direct ophthalmoscope, there is a marked obscuration of fundus detail, in that even the margins of the optic nerve head are not clearly defined because of the PCO $[19,20]$. 
Barman et al [21] reported a software for assessing PCO, in the POCO man software, images are analyzed by a set protocol of defining the area of the posterior capsule, removing the Purkinje light reflexes by intensity segmentation, contrast enhancement, filtering to enhance low-density PCO, and variance analysis using a co-occurrence matrix to assess the texture. It provides a semi-objective assessment of PCO and is valid and repeatable. Another system that captures high-resolution images is the EAS-1000 system (Scheimpflug video photography).

However, the IOL material has been seen to significantly influence the scatter light density measurements and thus the intensity of PCO quantified by this system cannot be directly compared with different optic materials. This makes the system less applicable to evaluating PCO $[22,23]$. Moreno et al [24] reported the use of optical coherence tomography (OCT-1) to quantify PCO and to discriminate between different types of PCO. PCO evaluation with OCT is based on peak intensity (PI) and posterior capsule thickening (PCT), with PCT indicating the distance between two reflectivity spikes with an approximate axial resolution of $10 \mu \mathrm{m}$.

Invasive Surgical removal of capsular opacity is considered in selected cases as surgery-related complications like vitreous loss and endophthalmitis are at higher rates in surgical removal. Surgical removal is done in cases of visual axis opacification in young children, thick PCO, and cases where $\mathrm{Nd}$ : YAG laser capsulotomy is ineffective in clearing the visual axis [20]. A non-Invasive procedure such as Nd: YAG laser capsulotomy was introduced as an effective procedure, but it has many complications.

Gardner et al [8], analyzed 100 patients, who underwent Nd: YAG laser posterior capsulotomy. The study reported that $48 \%$ of the population had best-corrected visual acuity between $6 / 18$ to $6 / 6$ at 24 hours and at end of one week, 73\% of the entire population had a significant increase in visual acuity. In this study population, at the end of 3 months of the procedure, BCVA of $78 \%$ of the patients improved to $6 / 12-6 / 6$ and $20 \%$ of them improved to $6 / 36-6 / 18$ and 1 (2\%) patient had poor visual acuity following Nd: YAG laser capsulotomy. Hossain et al [17] in his study reported only a few patients to complain of reduction of near vision because miosis most commonly was found in focal central PCO, where distant vision is adequate to have a large pupil size.
After seven days of capsulotomy, 76\% of patients gained $6 / 12$ or better vision. Eighty percent of patients gained visual acuity of $6 / 12$ with optical correction after thirty days. On the other hand, 64\% of patients had pre-capsulotomy near vision.

< N10 and $16 \%$ of patients had N8. A few complications of the rise in intra-ocular pressure ruptured anterior hyaloid face, and IOL pitting after 7 days of capsulotomy was noted in his study.

Yazici et al [18] evaluated a two-year outcome of phacoemulsification combined with primary posterior curvilinear capsulorhexis (PPCC) in 93 eyes of 91 adult patients. PCO occurred in only two $(2.2 \%)$ patients. No serious complications such as retinal detachment and endophthalmitis were observed during the follow-up. They concluded that cataract surgery combined with PPCC is a safe procedure in adults. H Vijaya Pai et al [19] in 2019 in their study reported that phacoemulsification with continuous curvilinear capsulorrhexis, hydrodissection, and meticulous cortical clean-up before IOL insertion is known to be most efficacious in preventing PCO formation. All the IOLs used in their study were variants of a hydrophobic acrylic material which is known to have lesser PCO rates compared to silicone or polymethylmethacrylate (PMMA) materials, also it had a posterior square edge design which has been stated to be an important factor in preventing PCO. The other important factor stated was the presence of a continuous 360-degree posterior enhanced square edge with good apposition of the optic to the posterior capsule. The presence of such a continuous barrier is known to prevent the lens epithelial cell migration from the optic-haptic junction, toward the visual axis

Elevated IOP is recognized as the most common complication, although usually transient, following Nd: YAG laser capsulotomy. Thompson et al [10] reported that IOP typically begins to rise immediately after the laser capsulotomy, peaks at 3-4 h, but may remain elevated at $24 \mathrm{~h}$, and usually returns to baseline at 1 -week. In the present study, about $6 \%$ of the population showed a rise in IOP $>21 \mathrm{mmHg}$ at 1 st hour and the end of 1st day of the procedure. Complications following Nd: YAG laser posterior capsulotomy can occur which has been reported in the literature which includes elevated intraocular pressure, iris bleeding, intraocular lens damage, uveitis, cystoid macular edema (CME), retinal detachment, endophthalmitis, and macular hole $[11,12,13]$. 
Mukesh et al [20] in his study reported CME developed in 0.5 to $2.5 \%$ of cases, IOL damage was reported from 9.4 to $33 \%$ of cases and retinal detachment occurred in $1.6-1.9 \%$ of laser capsulotomy cases over 3 years $[25,26]$.

In the present study iris bleeding with minimal hyphema was noted in $4 \%$ of the population, intraocular lens damage in $2 \%$, and CME in $2 \%$ of the population. Hyphema resolved spontaneously with topical steroids and CME was treated with intravitreal steroids. <

Patients with intraocular lens damage are under observation and regularly followed up. There was no evidence of retinal detachment, endophthalmitis, or macular hole in the present study. The documented visual improvement of the subjects in this study confirms the efficacy of $\mathrm{Nd}$ : YAG laser in postoperative PCO and serves as the best option.

Fig-3:Posterior capsular opacification.

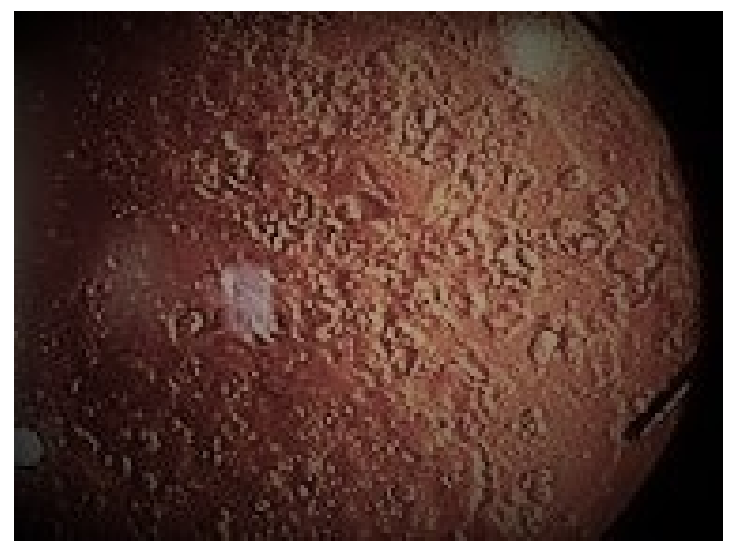

Fig-4: Post Nd: YAG capsulotomy opening.

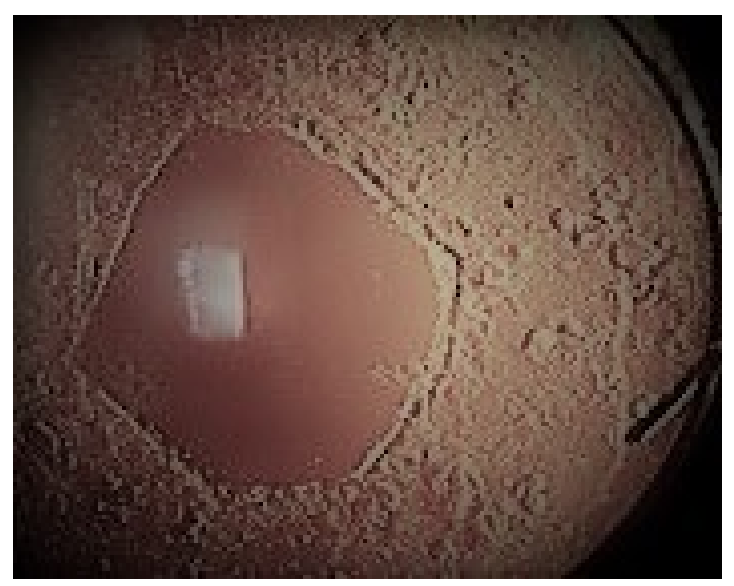

\section{Limitations}

The limitations of the present study were small sample size, a single surgical procedure with a limited period.
The current study also did not take into account the type of Intra-ocular lens causing PCO. Hence, a longer duration of the study period with a large sample size taking into consideration other factors contributing to $\mathrm{PCO}$, that thereby conclude the added information obtained.

\section{Conclusion}

Thus Nd: YAG laser posterior capsulotomy is a minimally invasive, safe, and effective procedure that provides an excellent visual outcome in the patients. The Nd: YAG laser is a noninvasive surgical tool that provides excellent posterior capsulotomies.

\section{What does the study add to the existing knowledge?}

From the above study, it is clear that Nd: YAG laser posterior capsulotomy is a safe and effective procedure for creating a capsular opening. The visual outcome in our patients showed significant visual improvement and the complication rate reported was also low. The reported complications were actively managed hence concluding the advantage of the procedure.

\section{Author's contribution}

Dr. Deepa $\mathbf{R}$ and Dr. V. Panimalar A. Veeramani conceived, planned, and carried out the study. Dr. V. Panimalar A. Veeramani assisted with data analysis, Dr. Deepa R. analyzed the data and wrote the manuscript with input from the other author.

\section{Reference}

01. Van Bree MC, van den Berg TJ, Zijlmans BL. Posterior capsule opacification severity, assessed with stray light measurement, as main indicator of early visual function deterioration. Ophthalmol. 2013;120(1)20-33.

doi: $\quad 10.1016 /$ j.ophtha.2012.07.050 [Crossref]

02. Werner L, Apple DJ, Pandey SK. Postoperative proliferation of anterior and equatorial lens epithelial cells- A comparison between various foldable IOL designs, In- References Buratto $L$, Osher R, Masket S, editors, Cataract Surgery in Complicated Cases. Thorofare, NJ, Slack Inc. 2000;399-417.

doi: $10.1016 / \mathrm{s} 0161-6420(01) 00674-1 \quad$ [Crossref] 
03. Aaron-Rosa D, Aron JJ, Griesemann M, Thyze IR. Use of neodymium- Yag laser to open the posterior capsule after lens implant surgery- a preliminary report. J Am Intraocul Implant Soc. $1980 ; 6(4) 352-354$.

doi: $10.1016 / s 0146-2776(80) 80036-x$ [Crossref]

04. Apple DJ, Solomon KD, Tetz MR, Assia EI, Holland EY,Legler UF, et al. Posterior capsule opacification. Surv Ophthalmol. 1992;37(2)73116.

doi: 10.1016/0039-6257(92)90073-3 [Crossref]

05. Baratz KH, Cook BE, Hodge DO. Probabality of Nd- Yag laser capsulotomy after cataract surgery in Olmsted County, Minnesota. Am J Ophthalmol. 2001;131(2)161-166.

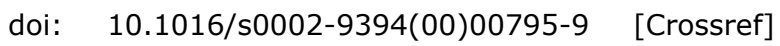

06. Jose RM, Bender LE, Boyce JF, Heatley C. Correlation between the measurement of posterior capsule opacification severity and visual function testing. J Cataract Refract Surg. 2005;31(3)534-542.

doi: $10.1016 /$ j.jcrs.2004.07.022 [Crossref]

07. Pandey SK, Apple DJ, Werner L, Maloof AJ, Milverton EJ. Posterior Capsule Opacification- A Review of the Aetiopathogenesis, Experimental and Clinical Studies and Factors for Prevention. Indian J Ophthalmol. 2004;52(2)99-112.

[Crossref]

08. Gardner M, Straatsma R. Nd- YAG laser posterior capsulotomy-first 100 cases at UCLA. J Ophthalmic Surge. 1985.

[Crossref]

09. Datiles MB, LasaMS. Evaluation of visual function following ND- YAG laser posterior capsulotomy. J Ophthalmol. 1997;104(8)12871293.

doi: $10.1016 / s 0161-6420(97) 30146-8$ [Crossref]

10. Thompson AM, Sachdev N, Wong T, Riley AF, Grupcheva CN, McGhee CN. The Auckland Cataract Study- 2-year postoperative assessment of aspects of clinical, visual, corneal topographic and satisfaction outcomes. $\mathrm{Br}$ J Ophthalmol. 2004;88(8)1042-1048.

doi: $10.1136 /$ bjo.2003.032581 [Crossref]
11. Steinert RF, Puliafito CA, Kumar SR, Dudak SD, Patel S. Cystoid macular edema, retinal detachment, and glaucoma after Nd- YAG laser posterior capsulotomy. Am J Ophthalmol. $1991 ; 112(4) 37380$.

doi: $10.1016 / s 0002-9394(14) 76242-7 \quad$ [Crossref]

12. Billotte C, Berdeaux G. Adverse clinical consequences of neodymium- YAG laser treatment of posterior capsule opacification. J Cataract Refract Surg. 2004;30(10)206471. doi: $10.1016 /$ j.jcrs.2004.05.003 [Crossref]

13. Keates RH, Steinert RF, Puliafito CA, Maxwell SK. Long-term follow-up of Nd- YAG laser posterior capsulotomy. J Am Intraocul Implant Soc. $1984 ; 10$ (2)164-168.

doi: $10.1016 / \mathrm{s} 0146-2776(84) 80101-9$ [Crossref]

14. Richter CU, Arzeno G, Pappas HR, Steinert RF, Puliafito C, Epstein DL. Intraocular pressure elevation following $\mathrm{Nd}$ - YAG laser posterior capsulotomy. Ophthalmol. 1985;92(5)636-640. doi: 10.1016/s0161-6420(85)33991-x [Crossref]

15. Yilmaz S, Ozdil MA, Bozkir N, Maden A. The effect of $\mathrm{Nd}$ - YAG laser capsulotomy size on refraction and visual acuity. J Refract Surg. $2006 ; 22(7) 719-721$.

[Crossref]

16. Küçüksümer Y, Bayraktar Ş, Şahin Ş, Yılmaz ÖF. Posterior capsule opacification 3 years after implantation of an Acry Sof and a Memory Lens in fellow eyes. J Cataract Refract Surg. $2000 ; 26(8) 1176-1182$.

doi: $10.1016 / \mathrm{s} 0886-3350(00) 00583-6$ [Crossref]

17. Hossain MI, Hossain MA, Hossain MJ. Visual outcome after Nd- YAG laser Capsulotomy. J Armed Forces Med College, Bangladesh. 2009;5(2)29-31.

doi: $10.3329 /$ jafmc.v5i2.4580 [Crossref]

18. Yazici AT, Bozkurt E, Kara N, Yildirim Y, Demirok A, Yilmaz OF. Long-term results of phacoemulsification combined with primary posterior curvilinear capsulorhexis in adults. Middle East Afr J Ophthalmol. 2012;19(1)115. doi: $10.4103 / 0974-9233.92126$ [Crossref] 
19. Pai HV, Pathan A, Kamath YS. A comparison of posterior capsular opacification after implantation of three different hydrophobic square edge intraocular lenses. Indian J Ophthalmol. 2019;67(9)1424.

doi: 10.4103/ijo.IJO_219_19 [Crossref]

20. Patil M, Singh D, Vanathi M. Posterior Capsular Opacification- Mechanism, Prevention and Management. DOS TIMES. Sept-Oct;2016.

[Crossref]

21. Barman SA, Hollick EJ, Boyce JF, Spalton DJ, Uyyanonvara B, Sanguinetti $G$, et al. Quantification of posterior capsular opacification in digital images after cataract surgery. Invest Ophthalmol Vis Sci. 2000;41(12)3882-3892. [Crossref]

22. Saika S, Miyamoto T, Ishida I, Tanaka T, Okada $Y$, Nagane $Y$, et al. Comparison of Scheimpflug images of posterior capsule opacification and histological findings in rabbits and humans. J Cataract Refract Surg. $2001 ; 27(7) 1088$.

doi: $10.1016 / \mathrm{s} 0886-3350(00) 00860-9$ [Crossref]
23. Tanaka $Y$, Kato $S$, Miyata $K$, Honbo M, Nejima $R$, Kitano $S$, et al. Limitation of Scheimpflug video photography system in quantifying posterior capsule opacification after intraocular lens im plantation. Am J Ophthalmol. 2004;137(4)732. doi: 10.1016/j.ajo.2003.11.011 [Crossref]

24. Moreno-Montanes J, Alvarez A, Maldonado MJ. Objective quantification of posterior capsule opacification after cataract surgery, with optical coherence tomography. Invest Ophthalmol Vis Sci. 2005;46(11)3999.

doi: 10.1167/iovs.04-1531 [Crossref]

25. Daniel WW. Determination of sample size for estimating proportions. Biostatistics $A$ found ation for analysis Health Sci. 1999;8;189-90.

doi: 10.1002/1097-0258(20010130)20:2<324: :AIDSIM635>3.0.CO;2-O [Crossref]

26. Prajna NV, Ellwein LB, Selvaraj S, Manjula K, Kupfer C. The madurai intra ocular lens study IV posterior capsular opacification. Am J Ophthalmol. 2000;130(3)304-309.

doi: 10.1016/s0002-9394(00)00481-5 [Crossref] 